\title{
Modeling and Vibration Suppression of a Flexible Structure in SimMechanics
}

\author{
Mehmet Uyar ${ }^{1 *}$ \\ 1* Bayburt University, Faculty of Engineering, Departmant of Mechanical Engineering, Bayburt, Turkey, (ORCID: 0000-0003-3511-7682), mehmuyar@gmail.com
}

(1st International Conference on Applied Engineering and Natural Sciences ICAENS 2021, November 1-3, 2021)

(DOI: 10.31590/ejosat.1011316)

ATIF/REFERENCE: Uyar, M. (2021). Modeling and Vibration Suppression of a Flexible Structure in SimMechanics. European Journal of Science and Technology, (28), 766-770.

\begin{abstract}
In this work, modeling and simulation of a flexible cantilever beam are investigated in SimMechanics and then, vibration results are verified with the finite element (FE) model in ANSYS. Flexible beam model based on SimMechanics is created in MATLAB, while the FE model is established in ANSYS. In the system, inputs are determined as a force base actuator and disturbance force. Outputs of the system are selected as displacement and acceleration responses at the endpoint of flexible beam. Undamped natural frequencies are determined by modal analysis in ANSYS and frequency analysis in MATLAB. Transient analyses are achieved to obtain the vibration responses. For the open loop responses, the displacement and acceleration vibration results are verified using step and harmonic excitations. The closed-loop control with PID controller is applied to the FE and SimMechanics models to control the endpoint position. The open and closed-loop vibration results are indicated for different controller gains. It observed that open and closed-loop results are successfully matched well with the FE model and SimMechanics. The accuracy of flexible beam model based on SimMechanics is verified with the FE model.
\end{abstract}

Keywords: Flexible beam model, Finite element model, Harmonic excitation, SimMechanics.

\section{SimMechanics ile Esnek Bir Yapının Modellenmesi ve Titreşim Sönümlemesi}

$\ddot{O} \mathbf{z}$

Bu çalışmada, SimMechanics'te esnek bir kirişin modellenmesi ve simülasyonu incelenmiş ve ardından ANSYS'te sonlu elemanlar (FE) modeli ile titreşim sonuçları doğrulanmıştır. MATLAB'de SimMechanics tabanlı esnek kiriş modeli oluşturulurken, FE modeli ANSYS'de kurulmuştur. Sistemin girdileri, bir kuvvet tabanlı uyarıcı ve bozucu kuvvet olarak belirlenir. Sistemin çıkışları, esnek kirişin uç noktasındaki yer değiştirme ve ivme sinyalleri olarak seçilir. Sönümsüz doğal frekanslar, ANSYS'de modal analiz ve MATLAB'da frekans analizi ile belirlenir. Titreşim cevaplarını elde etmek için geçici analizler yapılır. Açık döngü cevapları için, yer değiştirme ve ivme titreşim sonuçları, adım ve harmonik uyarılar kullanılarak doğrulanır. Uç nokta konumunu kontrol etmek için FE ve SimMechanics modellerine PID kontrolörlü kapalı döngü kontrol uygulanır. Açık ve kapalı döngü titreşim sonuçları, farklı kontrolör kazançları için belirlenmiştir. Açık ve kapalı döngü sonuçlarının, FE modeli ve SimMechanics ile başarılı bir şekilde eşleştirildiği gözlemlenmiştir. SimMechanics tabanlı esnek kiriş modelinin doğruluğu FE modeli ile doğrulanmıştır.

Anahtar Kelimeler: Esnek kiriş modeli, Sonlu elemanlar modeli, Harmonik uyarım, SimMechanics.

* Corresponding Author: mehmuyar@gmail.com 


\section{Introduction}

In many engineering areas, flexible structures are commonly used, such as, in particular, robotic systems and aerospace components designed for less weight structures (Mirafzal, Khorasani and Ghasemi, 2016). Dynamic modeling of flexible structures is more critical in these applications due to less rigid. Also, these structures are more sensitive to dynamic forces. Therefore, the modeling and vibration analysis of flexible structures are an important step to verify with the experimental studies. In many studies, the varied analytical approaches have been used to determine their dynamic behavior.

For simple vibration analysis, modeling of continuous structures such as beams can model as lumped mass model (Simeng et al., 2016), which are a series masses in a multi-degree of freedom system. Nevertheless, the accuracy of these models has limited (Meirovitch L, 2001). Some researchers offered new techniques to model the dynamic characteristics of a beam. Whalen (Whalen, 2008) modeled the transverse vibrations of the beam structure using Euler-Bernoulli beam theory, which ignores the possibility of coupled torsional-flexural bending motions. With similar analytical method, the characteristic equation of two separate beams, that is a function of eigenvalues, its sectional flexibility and the position of crack is obtained by Lin (Lin, 2004) using the Timoshenko beam theory. In Ref. (Shafiei and Khaji, 2011), an analytical method which is assume to support Timoshenko beam theory is developed by Shafiei and Khaji in order to evaluate the forced vibration response of beam with sectional flexibility.

The finite element method (FEM) that is one of the numerical methods, has been widely used for the dynamic modeling of flexible structures. Summarizing the works done, Zeng et al.(Zeng et al., 2017) modeled a cantilever beam by using FEM and then, studied the dynamic characteristic analysis of beam occurred in different crack types. Won et al. (Won, Lee and Chung, 2018) presented the dynamic responses of the stick-slip vibrations of a beam by applying the harmonic base excitation. FE method is used to model the dynamic behavior of the beam. Also, Mirafzal et al. (Mirafzal, Khorasani and Ghasemi, 2016) developed the equation of motion of a cantilever beam using the discrete standard formulation. In Ref. (Altunışık, Okur and Kahya, 2017), for numerical solutions, the FE model of a cantilever beam with a hollow circular cross-section is created in ANSYS. A detailed study is presented by authors on the vibration-based damage detection and modal parameter identification. Also, for the dynamic and static analysis of beam structures, Dona et al. (Donà et al., 2015) presented a beam FE model able to simulate such as longitudinal, rotational and transversal elastic spring. Castel et al. (Castel, Vidal and François, 2012) developed a macro-finiteelement (MFE) modeling method to calculate the deflection of the reinforced concrete beam.

Because of less rigidity of the flexible beams, unwanted vibration control is a critical step for performance criteria in many engineering applications. In literature, as presented in Ref. (Mirafzal, Khorasani and Ghasemi, 2016), vibration control of a cantilever beam is done with the active control method utilizing both a genetic algorithm and discrete quadratic function. Alhazza et al. (Alhazza, Nayfeh and Daqaq, 2009) improved the controller with acceleration signal as feedback to minimize the vibrations of a beam utilizing an actuator and sensor. With a novel control method in Ref. (Chen, Cai and Pan, 2009), an experimental study of a flexible plate is presented employing delayed-feedback control for effective vibration suppression.

In literature above, many studies have been studied on numerical and analytical methods to model the dynamic characteristics of flexible structures. Especially, the FE method is widely used for dynamic modeling of the beam. However, it is limited, or none studies on the modeling of flexible structures in flexible beam model based on SimMechanics, in particular for rigid structures, SimMechanics is commonly used. In this work, both the FE model and SimMechanics model of a flexible cantilever beam are studied in open and closed-loop system. The FE model is created in ANSYS while SimMechanics model is established in MATLAB/Simulink. The accuracy of the SimMechanics model is verified with the FE method by using step and harmonic excitation. Performance of numerical models is investigated with the uncontrolled and controlled vibration results.

\section{Flexible Beam Model by SimMechanics}

The flexible beam model of a cantilever beam considered in this study is created with the block diagram by using SimMechanics library in MATLAB/Simulink. The block diagram for SimMechanics model is shown in Fig. 1.

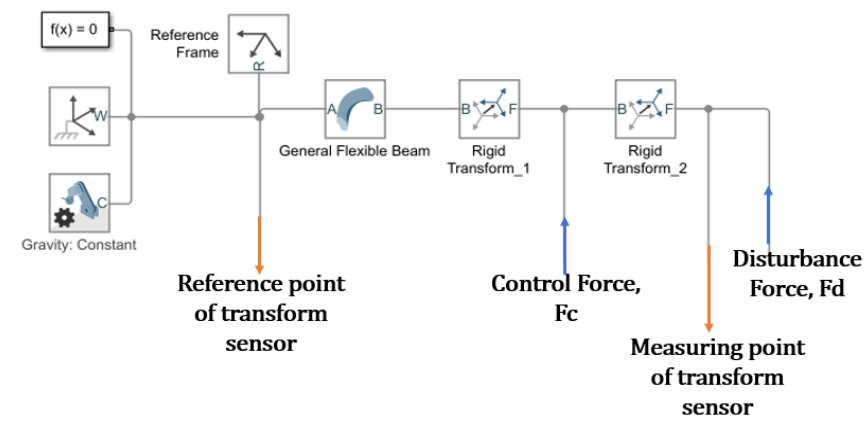

Fig. 1 Flexible beam model

SimMechanics model shown in Fig. 1 consists of five main sections: reference frame, flexible beam element, rigid transforms, inputs and outputs. Reference frame is used to describe the flexible cantilever beam model in general coordinates at $\mathrm{x}, \mathrm{y}, \mathrm{z}$-axis and, it is selected as reference point of transform sensor. Also, reference frame in block diagram is connected to the general flexible beam element. Flexible beam element can use to model the beam that has linear, elastic bending, axial and torsional deformations. Each flexible beam element has connection and reference frames called A and B to connect the other blocks. The connection frames are located at the endpoint of the beam element while reference frames which is the internal reference of the beam element are placed to connect to the previous connection port. So, general coordinate axes of the reference frame are moved from port A to port B by the connection and reference frames. The material properties and dimensions of the flexible beam are defined in the flexible beam element. The material properties are taken as the density of $7750 \mathrm{~kg} / \mathrm{m}^{3}$, elastic modulus of $210 \mathrm{GPa}$ and poison ratio of 0.3 . Dimensions of the cantilever beam are chosen as length $\mathrm{x}$ height $\mathrm{x}$ width of $600 \times 20 \times 3.2 \mathrm{~mm}^{3}$.

The flexible beam element uses the proportional damping method to define the damping of the system. In the proportional damping method, damping matrix is defined as a linear combination of the mass and stiffness matrices by using mass 
$\alpha$ and stiffness $\beta$ coefficients. Damping coefficients for flexible cantilever beam are chosen as $\alpha=0.133378$ and $\beta=0$.

In order to specify the positions of the actuator and sensor in the system, rigid transform is utilized in block diagram of the flexible beam model. Position of the control force Fc is described with Rigid Transform 1 at distance $260 \mathrm{~mm}$ from the root while Rigid Transform 2 is used to define the disturbance force Fd and transform sensor at distance $10 \mathrm{~mm}$ from endpoint of the flexible cantilever beam. Transform sensor which have two connection port called reference point $\mathrm{B}$ and measured point $\mathrm{F}$, is utilized to measure the displacement and acceleration signals placed at the endpoint of the system. Therefore, in the system, inputs are defined as disturbance and control forces while outputs are chosen as the displacement and acceleration signals obtained from the transform sensor.

\section{Finite Element Model by ANSYS}

In this section, finite element (FE) model shown in Fig. 2 is created to verify the SimMechanics model of a flexible cantilever beam.

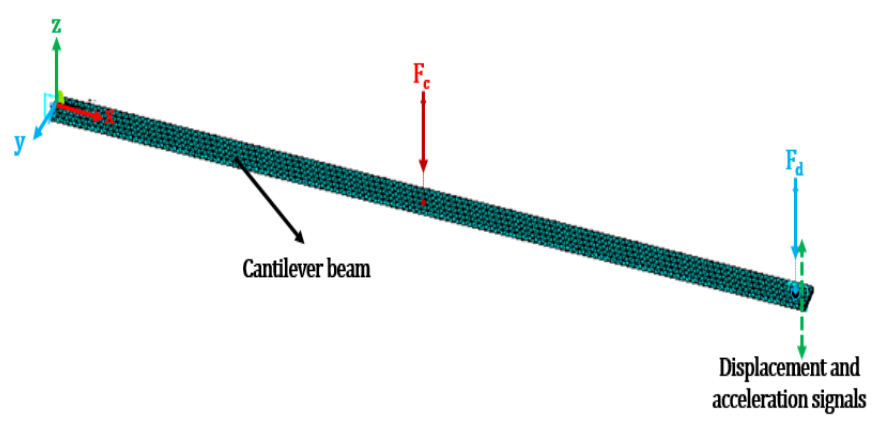

Fig. 2 Finite element model

The FE model is established in ANSYS by using SOLID92 and MASS21 elements. SOLID92 element is used to model the flexible cantilever beam as a solid model while MASS2 1 element is utilized to define the payload of $0.054 \mathrm{~kg}$ at the endpoint of the flexible cantilever beam. Payload is considered at a distance 10 $\mathrm{mm}$ from the tip point. For the FE model, the system has 2998 elements and 6676 nodes in total since element size is taken as 5 $\mathrm{mm}$ to generate the meshing of FE model.

\section{Modal Analysis}

In order to compare the natural frequencies of the $\mathrm{FE}$ and SimMechanics models, modal analysis is performed. The first natural frequencies which are determined using both ANSYS and SimMechanics, are obtained as $5.737 \mathrm{~Hz}$ for FE model and 5.737 $\mathrm{Hz}$ for SimMechanics model.

Time parameters of transient analysis are determined by undamped natural frequencies of the beam. With the first natural frequency by corresponding bending mode shape, the time step dt is calculated as $\mathrm{dt}=1 / 5.737 / 20 \mathrm{~s}$ and settling time tson is taken as $20 \mathrm{~s}$.

\section{Verification of Open Loop Responses}

In order to verify SimMechanics model, step and harmonic excitations for open loop responses are applied to the FE model and flexible beam model. Displacement and acceleration simulation results are shown in Fig. 3 for step input and Fig. 4 for harmonic excitation.

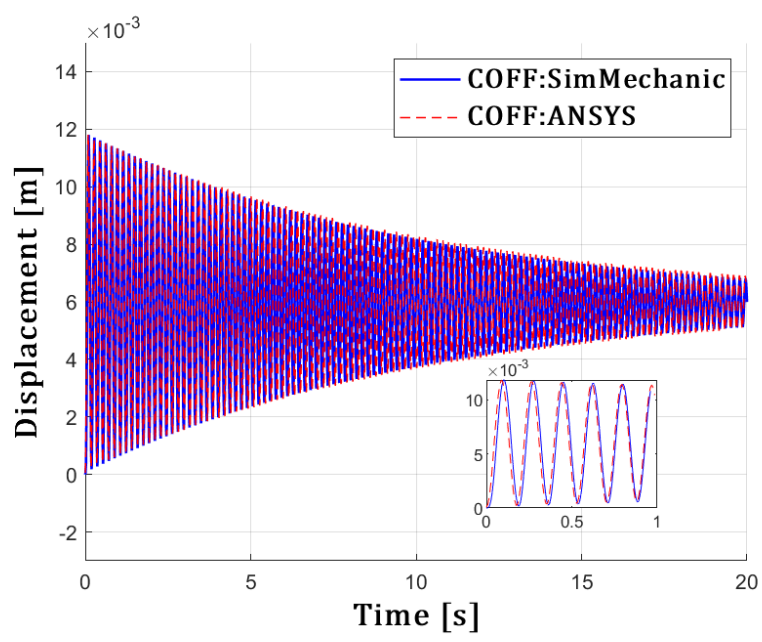

(a)

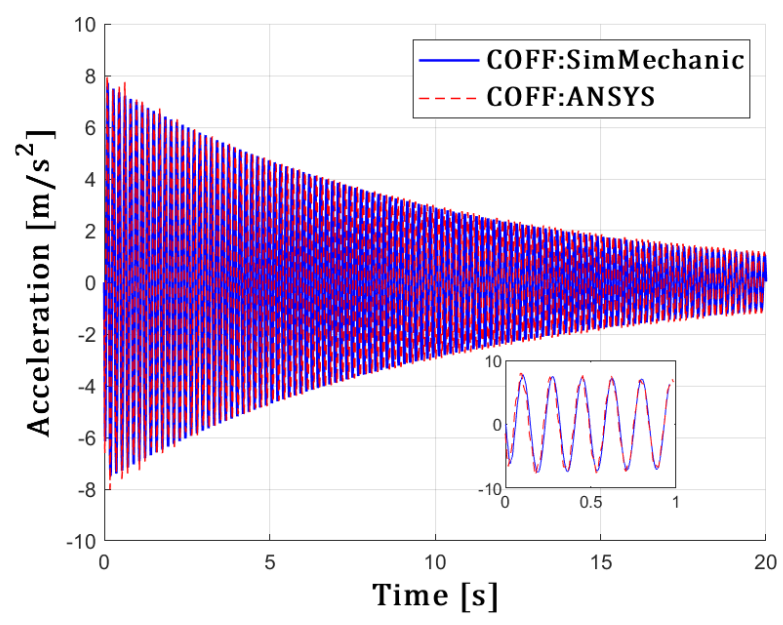

(b)

Fig. 3 Open loop responses for step input, a) displacement and b) acceleration

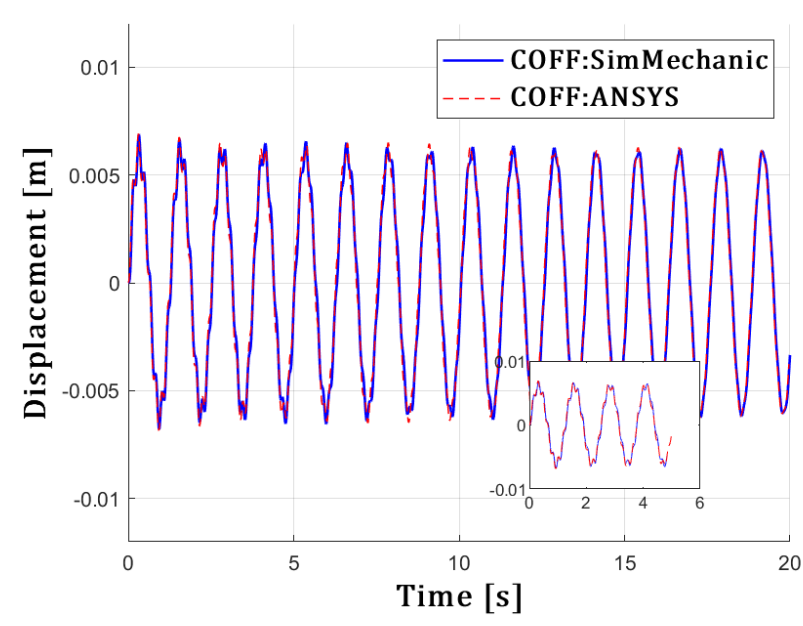

(a) 


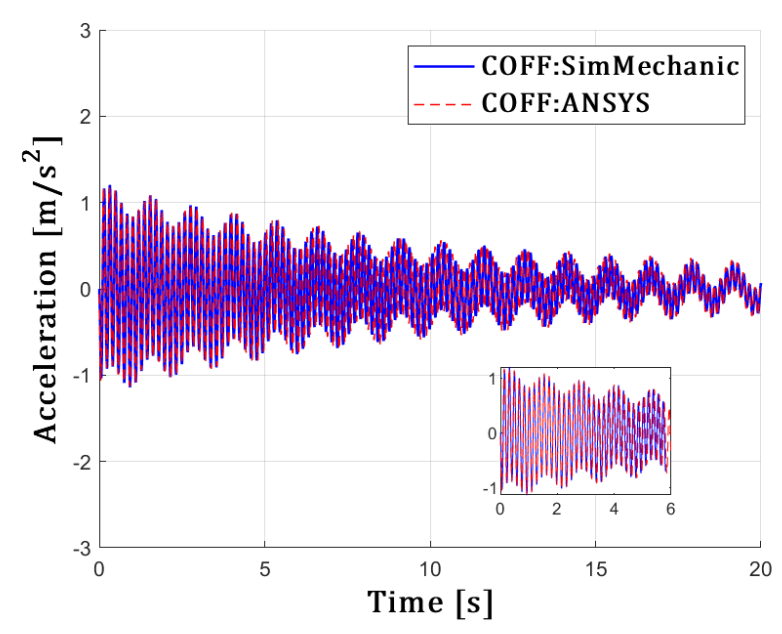

(b)

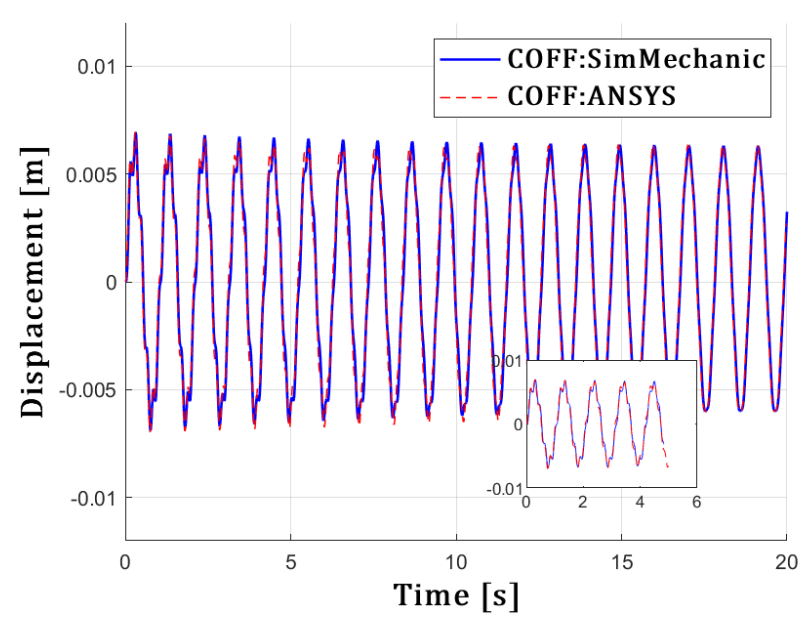

(c)

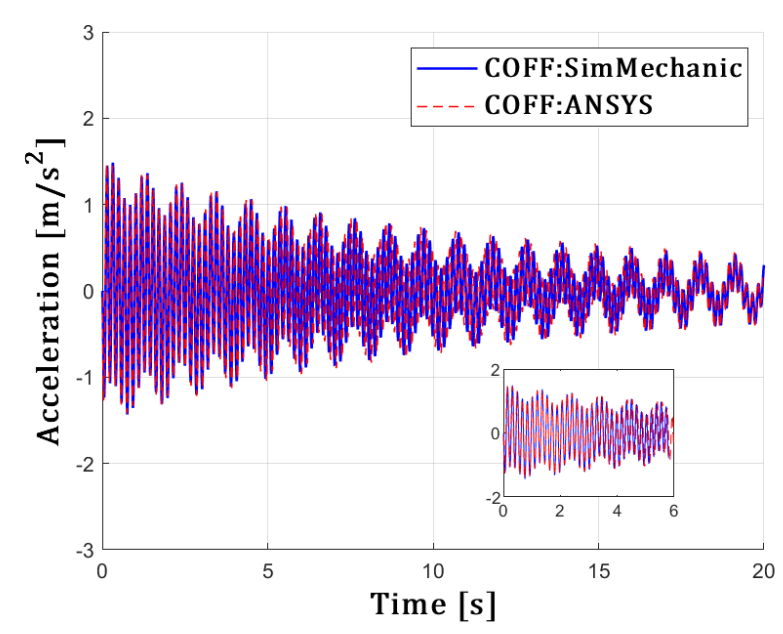

(d)

Fig. 4 Time responses for a-b) $5 \mathrm{~Hz}$ and c-d) $6 \mathrm{~Hz}$ harmonic excitation, a-c) displacement and b-d) acceleration

Vibration responses are shown for step amplitude of $1 \mathrm{~N}$ and harmonic excitations of 5 and $6 \mathrm{~Hz}$. It is observed that the results of flexible beam model are successfully matched with the FE simulation. The fitness values (FV) of the root mean square (RMS) of vibration responses are calculated to observe how fit the SimMechanics model according to the FE model. Firstly, RMS values are calculated and then, FV is computed according to the reference RMS values. RMS values of the simulation results in SimMechanics are considered for comparison. For step input, as shown in Fig. 3, RMS and FV values are found as $6.3543 \times 10^{-3}$ $\mathrm{mm}$ and $6.3289 \times 10^{-3} \mathrm{~mm}, 99.61 \%$ for displacement vibration response and, $2.7065 \mathrm{~m} / \mathrm{s}^{2}$ and $2.7343 \mathrm{~m} / \mathrm{s}^{2}, 98.98 \%$ for acceleration vibration response, respectively. For harmonic excitations, those values are obtained as $99.98 \%, 99.94 \%$ for displacement vibration response and $97.88 \%, 97.88 \%$ for acceleration vibration response, separately. When the FV values of vibration results are compared, the accuracy of SimMechanics model is verified with the FE model in open loop system.

\section{Closed-loop Responses by PID Control}

The closed-loop block diagram is presented in Fig. 5. Fd is disturbance force applied at the free point to excite the beam. The vibrations $\mathrm{y}(\mathrm{t})$ during the excitation is occurred at tip point. $\mathrm{y}(\mathrm{t})$ is simultaneously obtained as displacement signals at endpoint and is defined as feedback. The PID controller is used for the closedloop vibration control. The controller gains that are proportional $\mathrm{Kp}$, integral $\mathrm{Ki}$ and derivative $\mathrm{Kd}$ coefficients, are determined by trial-and-error method by considering the minimum settling time and overshoot. The instantaneous error $\mathrm{e}(\mathrm{t})$ is computed by subtracting the reference value from the feedback value. Then, $\mathrm{e}(\mathrm{t})$ is applied to the controller as input. The actuation signal achieved using the output of controller is used as control force Fc in the block diagram. Fc is applied to the beam to reduce the vibrations occurred at the endpoint.

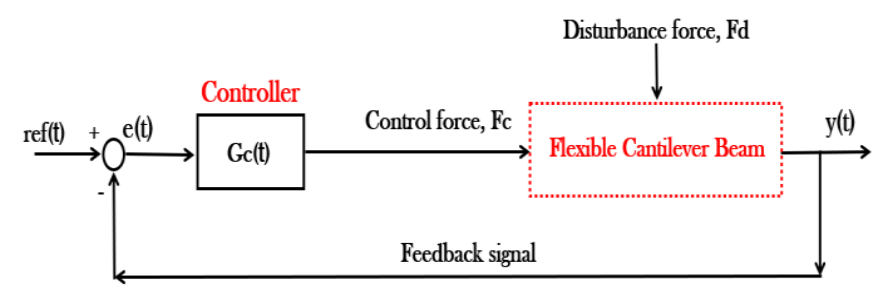

Fig. 5 Closed-loop block diagram

The controlled time responses shown in Fig. 6 are obtained for various controller gains.

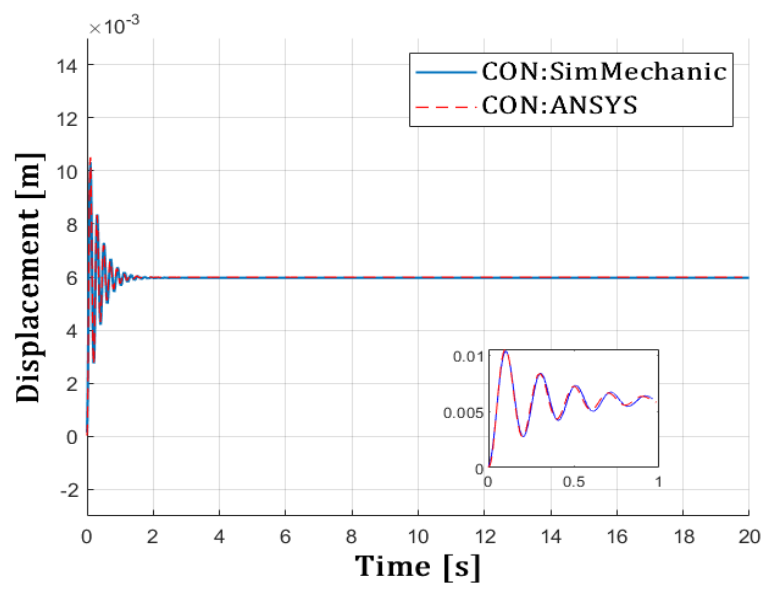

(a) 


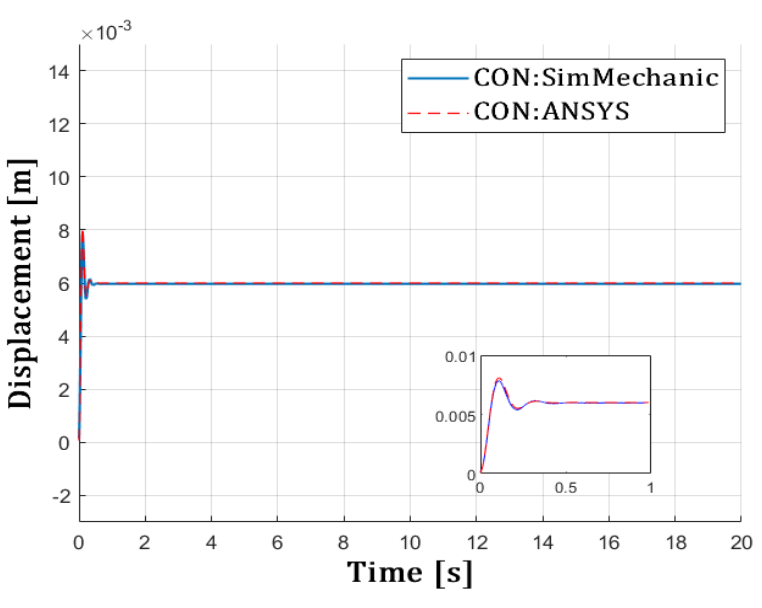

(b)

Fig. 6 Closed-loop responses for step input, a) $K_{p}=100, K_{i}=0$,

$$
\left.\mathrm{K}_{\mathrm{d}}=0 \text { and } \mathrm{b}\right) \mathrm{K}_{\mathrm{p}}=100, \mathrm{~K}_{\mathrm{i}}=0, \mathrm{~K}_{\mathrm{d}}=5
$$

As seen from Fig. 6, controlled vibration responses are presented for the FE and SimMechanics methods. Different controller gains are studied. It can be seen from Fig. 6 that the obtained vibration results agree well with the FE and SimMechanics simulations. The amplitude of vibrations is reduced with the PID controller. The settling time decreases by the closed-loop control. Therefore, dynamic performance of the flexible beam can be developed. The settling time of controlled vibration responses according to open loop responses is successfully minimized.

To compare the flexible beam model based on SimMechanics with the FE model, FV values of closed-loop vibration responses are calculated as $99.96 \%$ for $\mathrm{K}_{\mathrm{p}}=100, \mathrm{~K}_{\mathrm{i}}=0, \mathrm{~K}_{\mathrm{d}}=0$, and $99.95 \%$ for $\mathrm{K}_{\mathrm{p}}=100, \mathrm{~K}_{\mathrm{i}}=0, \mathrm{~K}_{\mathrm{d}}=5$, respectively. For the displacement vibration results, it is observed that the SimMechanics model is matched well with the FE model in the closed-loop system.

\section{Conclusions}

The open and closed-loop systems for a flexible cantilever beam are studied using the FE method and simulation based on the SimMechanics in MATLAB. For open loop system, the disturbance force is excited to the beam at endpoint. Displacement and acceleration responses are obtained at the tip point of the beam. Vibration responses of step and harmonic excitation are presented for the displacement and acceleration results. For the closed-loop system, displacement responses for step input are obtained using the FE model and SimMechanics approach. The effect of controller gains is investigated for displacement results in the FE and SimMechanics models. Successfully, the unwanted vibrations of beam are reduced by employing the PID control.

\section{References}

Alhazza, K. A., Nayfeh, A. H. and Daqaq, M. F. (2009) 'On utilizing delayed feedback for active-multimode vibration control of cantilever beams', Journal of Sound and Vibration. Academic Press, 319(3-5), pp. 735-752. doi: 10.1016/J.JSV.2008.06.052.

Altunışık, A. C., Okur, F. Y. and Kahya, V. (2017) 'Modal parameter identification and vibration based damage detection of a multiple cracked cantilever beam', Engineering Failure Analysis, 79(April), pp. 154-170. doi: 10.1016/j.engfailanal.2017.04.026.
Castel, A., Vidal, T. and François, R. (2012) 'Finite-Element Modeling to Calculate the Overall Stiffness of Cracked Reinforced Concrete Beams', Journal of Structural Engineering, 138(7), pp. 889-898. doi: 10.1061/(asce)st.1943-541x.0000520.

Chen, L. X., Cai, G. P. and Pan, J. (2009) 'Experimental study of delayed feedback control for a flexible plate', Journal of Sound and Vibration. Academic Press, 322(4-5), pp. 629651. doi: 10.1016/J.JSV.2008.11.045.

Donà, M. et al. (2015) 'An efficient two-node finite element formulation of multi-damaged beams including shear deformation and rotatory inertia', Computers and Structures, 147, pp. 96-106. doi: 10.1016/j.compstruc.2014.10.002.

Lin, H. P. (2004) 'Direct and inverse methods on free vibration analysis of simply supported beams with a crack', Engineering Structures, 26(4), pp. 427-436. doi: 10.1016/j.engstruct.2003.10.014.

Meirovitch L (2001) Fundamentals ofVibrations. International Edition. New York: McGraw-Hill.

Mirafzal, S. H., Khorasani, A. M. and Ghasemi, A. H. (2016) 'Optimizing time delay feedback for active vibration control of a cantilever beam using a genetic algorithm', JVC/Journal of Vibration and Control, 22(19), pp. 4047-4061. doi: $10.1177 / 1077546315569863$.

Shafiei, M. and Khaji, N. (2011) 'Analytical solutions for free and forced vibrations of a multiple cracked Timoshenko beam subject', Acta Mechanica, 97, pp. 79-97. doi: 10.1007/s00707-011-0495-x.

Simeng, L. et al. (2016) 'Mode-specific damage identification method for reinforced concrete beams: Concept, theory and experiments', Construction and Building Materials, 124(2016), pp. 1090-1099.

Whalen, T. M. (2008) 'The behavior of higher order mode shape derivatives in damaged, beam-like structures', Journal of Sound and Vibration, 309(3-5), pp. 426-464. doi: 10.1016/j.jsv.2007.07.054.

Won, H. I., Lee, B. and Chung, J. (2018) 'Stick-slip vibration of a cantilever beam subjected to harmonic base excitation', Nonlinear Dynamics. Springer Netherlands, 92(4), pp. 18151828. doi: 10.1007/s11071-018-4164-7.

Zeng, J. et al. (2017) 'Dynamic characteristic analysis of cracked cantilever beams under different crack types', Engineering Failure Analysis. Elsevier Ltd, 74, pp. 80-94. doi: 10.1016/j.engfailanal.2017.01.005. 